\title{
Study on post partum intrauterine contraceptive device practices and causes for discontinuation of PPIUCD at follow up in a tertiary hospital
}

\author{
Radhika Chethan, Anitha G. S.*, Savitha C.
}

Department of Obstetrics and Gynecology, Bangalore Medical College and Research Institute, Bangalore, Karnataka, India

Received: 24 March 2018

Accepted: 01 May 2018

*Correspondence:

Dr. Anitha G. S.,

E-mail: aninaik85@gmail.com

Copyright: () the author(s), publisher and licensee Medip Academy. This is an open-access article distributed under the terms of the Creative Commons Attribution Non-Commercial License, which permits unrestricted non-commercial use, distribution, and reproduction in any medium, provided the original work is properly cited.

\begin{abstract}
Background: Post partum contraception is the best evidence based intervention in prevention of pregnancy and abortion related maternal morbidity and mortality in the developing countries. The unmet need for contraception among women in the postpartum period can be effectively fulfilled by post partum insertion of IUCD, in a single visit under the Government scheme of providing free maternity services during institutional delivery. Despite optimal efforts by family planning program, very few couples are opting for spacing methods and lack of awareness has resulted in discontinuation of family planning methods particularly PPIUCD. This study is designed to study the practices of PPIUCD and causes for discontinuation at follow up in our hospital. The objectives of the study were study PPIUCD practices at Vanivilas hospital; causes for discontinuation of PPIUCD.

Methods: Prospective study done at Vanivilas hospital attached to Bangalore Medical College and Research Institute from January 2014 to December 2014. Women admitted and delivered at VVH, were counselled. CuT 380A was inserted in accepters who fulfilled the Medical Eligibility Criteria and had no contraindications for PPIUCD. They were followed up till June 2016.

Results: There were 2072 PPIUCD insertions in one year, out of which 1244 were post placental, 139 were in immediate postpartum and 689 were intra caesarean insertions. Fifty four (54) women discontinued PPIUCD during follow up .Main causes for removal were menstrual abnormalities (19), pain abdomen (13), wanting sterilisation procedure (12) and marital disharmony.

Conclusions: PPIUCD is an effective, safe, reversible method of long term contraception with high reported expulsion and low perforation rate, compared to interval insertion. More research is needed in the field of PPIUCD to enhance awareness and acceptance in the community. Awareness and counselling the eligible couples during ante natal care can improve acceptance and compliance of PPIUCD continuation rates.
\end{abstract}

Keywords: Post-partum intrauterine contraceptive device, Post placental, Client, Caesarean delivery, Expulsion, Contraception, Counselling

\section{INTRODUCTION}

Intra uterine contraceptive device (IUCD) to prevent pregnancy is among the oldest methods of contraception. ${ }^{1}$ The modern IUCD is a highly effective, safe, private, long acting, coitus independent and rapidly reversible method of contraception with fewer side effects. ${ }^{2}$
Intrauterine contraception is the most cost-effective method of contraception today. Many women also find the IUCD to be very convenient, because it requires little attention once it is inserted. ${ }^{3}$ Increasing numbers of women in India are having their babies born in hospitals after introduction of JSY and JSSK. ${ }^{4}$ It allows opportunity for the state to provide PPIUD in a big way. 
Many of these women welcome the opportunity to delay their next pregnancy when are counseled well. The postpartum insertion of an IUCD is likely to bring about a revolutionary change in contraceptive use in the country. ${ }^{5}$ Opportunity for a success is excellent, because

- Introduction of JSY has increased institutional deliveries.

- Labor room is attended by large number of beneficiaries every day.

- Delivery provides a convenient opportunity for the woman to receive IUCD services.

- This is particularly important for women who have limited access to medical care.

- Having just given birth, the woman is clearly not pregnant.

- She is likely to be motivated to consider long-acting methods.

IUCD can be inserted safely at any time during the first $48 \mathrm{~h}$ after delivery, can also be inserted after 6 weeks postpartum (Extended PP) and after an abortion (PostAbortal). ${ }^{6,7}$

Despite the many advantages of the IUCD as a method of family planning, it generally suffers from unpopularity in India. ${ }^{8}$ In India, less than two percent of women use the IUCD as their modern contraceptive method of choice. National program provides incentives to health care providers to promote sterilization, and very little importance is given to IUD or other temporary contraceptive methods. In this environment, it is not surprising that use of temporary contraceptive methods in the country is limited to $10.2 \%$ and that of IUD only 1.8 $\%$ (NFHS 2006). ${ }^{8}$ During the last 20 years, use of the IUD has remained low. Recently, however, the MOHFW has been trying to increase the use of temporary methods. Recent studies estimate that prevention of unplanned and unwanted pregnancies could help avert 20-35\% of maternal deaths and as many as $20 \%$ of infant deaths. ${ }^{9}$

Our study is designed to study the practices of PPIUCD and causes for discontinuation at follow up in our hospital.

\section{Objectives}

- Overview PPIUCD practices at vanivilas hospital

- Causes for discontinuation of PPIUCD (removal on request)

\section{Case criteria}

\section{Inclusion criteria}

Cases who discontinued PPIUCD use (request removal). Both clinical visit and telephonic visit (removal out side)

\section{Exclusion criteria}

After spacing of 2 years, removal of ppiucd for partial expulsion, complete expulsion.

\section{METHODS}

Retrospective descriptive study done at Vanivilas hospital attached to BMCRI from January 2014 to December 2014.

\section{Insertion techniques}

\section{Post-placental insertion}

All necessary instruments (Copper T 380A, 2 ring forceps, Sim's speculum, over head lamp, Povidone Iodine, kidney tray, and cotton swabs) were arranged on an auxiliary table covered with a sterile drape. Insertion was performed by the consultant using modified Kelley placental forceps. The patient was placed in a lithotomy position with buttocks at the edge of the table. Aseptic techniques were enforced throughout the procedure.

The uterus was palpated to evaluate the height of the fundus and its tone. This is important to assess the size of the uterus to know whether the strings are likely to protrude through the cervix even when $\mathrm{CuT}$ is placed at fundus.

After performing the appropriate hand washing, a pair of sterile gloves was worn. The perineum was cleaned with povidone iodine. The perineum, labia, and vaginal walls were inspected for lacerations. HLD Sim's speculum was gently inserted into the vagina to visualize the cervix. The cervix and the vaginal walls were cleaned twice with cotton swabs soaked in povidone iodine solution with speculum in place. The anterior lip of the cervix was then gently grasped with the same ring forceps used earlier.

The IUCD was removed from the insertion sleeve and grasped with the modified Kelley forceps using no-touch technique. Once it is inserted in to lower uterine segment, other hand was moved to abdomen; and placed over the fundus and uterus was pushed gently upward to reduce the angle and curvature between the uterus and vagina. IUCD with forceps was moved upward until it can be felt at the fundus. Then the forceps were opened to release the IUCD and swept to side wall. Uterus was stabilized until forceps removal was complete. The cervical os was then gently inspected for the strings. Sims speculum was removed. She was allowed to take rest for some time.

\section{Intra-caesarean insertion of the IUCD}

Uterine cavity was inspected for presence of malformations following placental delivery, which would limit use of IUCD. The IUCD was removed from the insertion sleeve and placed on the sterile field. Uterus is stabilized by grasping it at fundus. IUCD is held between 
middle and index finger. It was inserted into the uterus through uterine incision and released at fundus of uterus. Hand was removed slowly from the uterus. Enough care was taken not to dislodge IUCD as hand is removed. Strings ware guided toward the lower uterine segment without disturbing IUCD'S fundal position. Enough care was taken not to include IUCD strings during uterine closure.

\section{Later prior to discharge}

- IUCD Client card, showing type of IUCD and date of insertion were prepared.

- She was informed about the IUCD side effects and normal postpartum symptoms.

- Woman was told when to return for IUCD follow-up/ PNC/newborn check-up.

- She was advised to come back any time she has-

- Foul smelling vaginal discharge different from the usual lochia.

- Lower abdominal pain, especially if accompanied by not feeling well, fever or chills,

- Feeling of being pregnant

- Suspicion that the IUCD has fallen out.

Review of PPIUCD by maintaining follow up registry, Clinic visit and Telephonic review.

\section{RESULTS}

The total number of deliveries in Vanivilas hospital from January 2014 to December 2014 was 17,289.

The total number of PPIUCD inserted from January 2014 to December 2014 was 2072 (11.98\%).

Table 1: Classification according timing of insertion of PPIUCD.

\begin{tabular}{|ll|}
\hline Type of PPIUCD & Number (\%) \\
\hline Post placental & $1244(60)$ \\
\hline Immediate post partum & $139(6.7)$ \\
\hline Intra caesarean & $689(33.3)$ \\
\hline
\end{tabular}

The majority of the cases were post placental followed by intra caesarean. This is due to the counseling during labor and the decreased difficulty in inserting PPIUCD in the post placental period. Immediate post partum PPIUCD was the least.

Table 2: Total number of women counseled for PPIUCD.

\begin{tabular}{|ll|}
\hline Counseled for PPIUCD & Number \\
\hline ANC & 15,768 \\
\hline Early Labor & 9,360 \\
\hline
\end{tabular}

In our hospital, maximum counseling was done during antenatal period, especially in the $3^{\text {rd }}$ trimester. We provided a cafeteria approach. We had our postgraduates counsel the women the advantages and the complications of PPIUCD and entered in their follow up sheet.

Table 3: Number of counseled women who agreed for PPIUCD.

\begin{tabular}{|ll|}
\hline Number of women who agreed & Number \\
\hline ANC counseling & 653 \\
\hline Early labor & 1280 \\
\hline Post partum & 139 \\
\hline
\end{tabular}

Among the women counseled for PPIUCD, it was noted that maximum acceptance was in early labor (61.77\%). The least acceptance was in the postpartum period.

Table 4: Number of cases followed up \& number of cases discontinued PPIUCD.

\begin{tabular}{|ll|}
\hline Total cases followed up & $\begin{array}{l}297(14.3 \%) \text { Clinic visit }- \\
43, \text { telephonic }-11\end{array}$ \\
\hline $\begin{array}{l}\text { Total number of cases } \\
\text { discontinued use }\end{array}$ & $54(2.6 \%)$ \\
\hline
\end{tabular}

We have followed up 297 cases, either through visit at our OPD (43) or by telephone (11). There were 54 cases that had discontinued PPIUCD.

Table 5: Classification based on age among discontinued

\begin{tabular}{|ll|}
\hline Age in years & $\begin{array}{l}\text { Number of women discontinued } \\
\text { PPIUCD }\end{array}$ \\
\hline $19-25$ & 45 \\
\hline $26-30$ & 8 \\
\hline $31-35$ & 0 \\
\hline $36-40$ & 1 \\
\hline
\end{tabular}

The highest percentage of those who discontinued PPIUCD was in the age group of 19-25 years. There were no cases that discontinued PPIUCD in the age group of 31-35.

Table 6: Classification based on insertion timing among discontinued.

\begin{tabular}{|ll|}
\hline Insertion timing & Number \\
\hline Post placental & 40 \\
\hline Immediate post partum & 1 \\
\hline Intra caesarean & 13 \\
\hline
\end{tabular}

Table 7: Follow up period at removal.

\begin{tabular}{|ll|}
\hline 6 weeks & $39(72.2 \%)$ \\
\hline$>7$ weeks -6 months & $8(14.8 \%)$ \\
\hline 7 months -1 year & $7(13 \%)$ \\
\hline$>1-2$ years & nil \\
\hline
\end{tabular}


Table 8: Causes for discontinuation.

\begin{tabular}{|ll|}
\hline Menstrual disturbances & 19 \\
\hline Pain (abdomen + back) & 13 \\
\hline Wanting sterilization (LTO) & 12 \\
\hline Thread not seen & 7 \\
\hline Marital disharmony & 2 \\
\hline WDPV & 1 \\
\hline
\end{tabular}

On the basis of timing of insertion of PPIUCD, the highest rate of discontinuance was among post placental insertion. This may be due to the increased insertion of PPIUCD in the post placental period.

Maximum removal of PPIUCD was in the follow up period of less than 6 weeks. There was no removal after 1 year.

Menstrual disturbance was the leading cause for discontinuation followed by pain. Another important cause for discontinuation was the decision of permanent sterilization taken by the client. There were 13 cases of pain abdomen or back. In 7 cases, the thread was missing and this was a cause for worry for the client.

Table 9: Correlation of causes with interval at follow up.

\begin{tabular}{|ll|lll|}
\hline & 6 weeks & 7 weeks -6 months & 7 months -1 year & Total \\
\hline Menstrual & 17 & 2 & - & 19 \\
\hline Pain & 11 & 2 & - & 13 \\
\hline Sterilization & 4 & 1 & 7 & 12 \\
\hline Thread not seen & 5 & 2 & - & 7 \\
\hline Marital disharmony & 2 & - & - & 2 \\
\hline WDPV & - & 1 & - & 1 \\
\hline Total & 39 & 8 & 7 & 54 \\
\hline
\end{tabular}

\section{DISCUSSION}

Helping couples understand their risk of unplanned pregnancy and ensuring that high quality postpartum family planning services are available to them is the objective of an ideal contraceptive counselling. Linking maternal child health and family planning services is critical to achieve healthy spacing of pregnancy (HSP). This led to the revival of post-partum IUCD in 2010. Majority of participants accepted the method when they were given information during early labour (1280) compared to antenatal counselling (653). Those patients who were willing to accept during the antenatal period become reluctant later as they are more exposed to rumours and myths regarding copper T. Many studies have shown that when the husband is involved in counselling and decision making the acceptance and continuation rates were higher. A randomized prospective study conducted by Smith et al in antenatal clinics in China, Scotland and South Africa in which some women received information on contraception in antenatal care and some did not, found no difference in subsequent contraceptive use ${ }^{\mathbf{1 0}}$. Mohammed et al observed that acceptance rate was the same during antenatal and postpartum counselling, 26.4 and $31.8 \%$, respectively.$^{1}$ One of the main observations at follow up was the missing strings. Kapp et al reported missing string rate in interval IUCD insertion to be $15.6 \%^{\mathbf{1 1}}$. There was limited literature regarding missing strings in PPIUCD insertion. Present study showed the significantly high occurrence of missing strings with postpartum IUCD (7). However ultrasound done showed PPIUCD insitu and counselling and reassurance encouraged them to continue with the device.
About 19 of women in the present study reported menstrual disturbances. This rate is higher than the rate of $0.1 \%$ reported among women in Paraguay ${ }^{\mathbf{1 2}}$. A limitation of the present study is that infection was based upon selfreport and was not corroborated by medical records or microbiological confirmation. 39 women $(72.2 \%)$, had their PPIUCD removed within the first six weeks of insertion. Women most commonly reported expected side effects of IUCDs as the reasons for the removal, including bleeding and abdominal pain. These findings suggest that there is room for strengthening PPIUCD counselling services, particularly regarding normal side effects and complications that arise from method use.

\section{CONCLUSION}

Counseling should include complications, particularly their temporary nature. Involvement of private sectors into PPIUCD program. Involvement of family members during counseling. Counseling during ANC may improve acceptance rate. Awareness / health education is of utmost importance for success of the programme. ${ }^{13}$ It is also important to arrange training on PPIUCD in order to increase knowledge and skills among healthcare providers. This will also further promote PPIUCD use and aid in reduction of the expulsion rates. Cash incentives to the accepter, motivator and of course provider would bring about a substantial progress in the PPIUCD use in developing countries like India ${ }^{4}$.

Funding: No funding sources

Conflict of interest: None declared

Ethical approval: The study was approved by the Institutional Ethics Committee 


\section{REFERENCES}

1. Mohamed SA, Kamel MA, Shaaban OM, Salem HT. Acceptability for the use of postpartum intrauterine contraceptive devices: assiut experience. Med Princ Pract. 2003;12:170-5.

2. Thomas D, Maluccio J. Fertility, contraceptive choice, and public policy in Zimbabwe. World Bank Econ Rev. 1996;10(1):189-222.

3. Grimes D, Schulz K, van Vliet H, Stanwood N. Immediate post-partum insertion of intrauterine devices: a cochrane review. Hum Reprod. 2002;17(3):549-54.

4. Maternal and Child Health Integrated Program and PPFP activities, WHO Report. Available at: http://www.k4health.org/sites/default/files/PPFPMee tingReport_formatted.pdf. Accessed on 3 March 2018.

5. Celen S, Möröy P, Sucak A, Aktulay A, Danişman N. Clinical outcomes of early post placental insertion of intrauterine contraceptive devices. Contraception. 2004;69:279-82.

6. Blanchard H, Mac Kaig C. ACCESS-FP Program. 2006. Available at: Postpartum contraception: http://www.k4health.org/sites/default/files/postpartu mabortion_English.pdf. Accessed on 3 March 2018.

7. Tatum HJ, Beltran RS, Ramos R, Van Kets H, Sivin I, Schmidt FH. Immediate post placental insertion of
GYNE-T 380 and GYNE-T 380 postpartum contraceptive devices: randomized study. Am J Obstet Gynecol. 1996;175(5):1231-5.

8. National Family Health Survey (NFHS-3) 2005-06.

9. IIPS (International Institute for Population Sciences), Mumbai, India; 2007.

10. Smith KB. Is postpartum contraceptive advice given antenatal of value? Contraception. 2002;65(3):23743.

11. Kapp N, Curtis KM. Intrauterine device insertion during the postpartum period: a systematic review.Contraception. 2009;80(4):327-36.

12. Eroğlu K, Akkuzu G, Vural G, Dilbaz B, Akın A, Taşkın L, et al. Comparison of efficacy and complications of IUD insertion in immediate post placental/early postpartum period with interval period: 1 year follow-up. Contraception. 2006;74(5):376-81.

13. Kumar S, Sethi R, Balasubramaniam S, Charurat E, Lalchandani K, Semba R, et al. Women's experience with postpartum intrauterine contraceptive device use in India. Reprod Health. 2014;11(1):32.

Cite this article as: Chethan R, Anitha GS, Savitha C. Study on post partum intrauterine contraceptive device practices and causes for discontinuation of PPIUCD at follow up in a tertiary hospital. Int $\mathbf{J}$ Reprod Contracept Obstet Gynecol 2018;7:2299-303. 